\title{
Orientação vocacional e promoção da saúde integral em adolescentes
}

\section{Vocational guidance and adolescent's health promotion}

\author{
Fernando Henrique Rezende Aguiar* \\ Universidade de Brasília - UNB, Distrito Federal, Brasília, Brasil \\ Maria Inês Gandolfo Conceição** \\ Universidade de Brasília - UNB, Distrito Federal, Brasília, Brasil
}

\begin{abstract}
RESUMO
Há uma estreita relação entre uma escolha vocacional de carreira consciente, e a saúde integral do ser humano. As práticas atuais de orientação vocacional e de carreira (OV) atuam da infância à aposentadoria, construindo autonomia e instrumentalizando os sujeitos para a elaboração do próprio projeto de vida. O Ministério da Saúde reconhece a importância do projeto de vida na promoção da saúde integral em adolescentes, que são considerados um grupo de alta vulnerabilidade. O objetivo desse estudo é, por meio de uma reflexão teórica, discutir as intervenções em OV que impactam na saúde integral de adolescentes. Articulou-se a literatura nacional e internacional sobre os temas e concluiu-se que o protagonismo juvenil é uma ponte válida entre as intervenções vocacionais e a promoção da saúde. As práticas de OV que promovem autoconhecimento, desenvolvimento vocacional e responsabilidade social podem contribuir para as políticas públicas de promoção da saúde integral.
\end{abstract}

Palavras-chave: Orientação vocacional, Promoção da saúde, Protagonismo juvenil.

\begin{abstract}
There is a close relation between vocational choice and human's integral health. Current practices in vocational guidance (VG) acts from childhood to retirement, promoting autonomy and preparing individuals to build-up their own life projects. The Ministry of Health highlights the importance of life project to promote adolescent's health, since this is a very vulnerable group. The objective of this study is, through theorist articulations, to discuss VG's interventions that may impact adolescent's health. The national and international literature was consulted leading to the conclusion that youth protagonism is like a bridge between VG and health promotion. The practices in VG that promotes self-knowledge, vocational development and social responsibility can contribute to public policies aimed at promoting young people's health.
\end{abstract}

Key-words: Vocational guidance, Health promotion, Youth protagonism.

\section{Orientação vocacional}


A orientação vocacional em seus primórdios foi, eminentemente, baseada na psicometria. Sua primeira grande expansão ocorreu no período da Revolução Industrial, já no final do século XIX. O objetivo naquele momento era encontrar 0 trabalho certo para cada trabalhador, com vistas ao aumento da produtividade e do lucro do empregador, a despeito das necessidades dos sujeitos. Havia a compreensão de que se a pessoa estivesse no trabalho adequado para suas características, consideradas inatas, estaria satisfeita e ajustada. Mais adiante, surgiram as teorias psicodinâmicas, desenvolvimentistas e psicossociais que passaram a reconhecer que outros aspectos também deveriam ser considerados ao se pensar em uma profissão e questionavam a existência de características imutáveis. Foi percebida a importância do autoconhecimento e de preparar o sujeito para construir seu próprio caminho profissional com autonomia e consciência, considerando características pessoais, culturais e sócioeconômicas (ABADE, 2005; LEVENFUS; BANDEIRA, 2009).

A orientação vocacional deve ser pensada dentro de um contexto sócio-histórico, ponderando-se que muitas vezes as condições do meio podem limitar a liberdade de escolha. Maia e Mancebo (2010), em pesquisa com jovens da classe média alta do Rio de Janeiro, perceberam que os jovens reproduzem um discurso individualista, baseado no mérito pessoal e na busca por satisfação das próprias necessidades. As autoras identificaram que tais adolescentes não se percebem capazes de promover mudanças sociais. Abade (2005) ressalta que a intervenção em orientação vocacional deve considerar o aspecto social, buscando nos referenciais teóricos os elementos para discutir e questionar a lógica do sistema capitalista e do mercado de trabalho, deixando claro para o adolescente que ele é um agente ativo que pode contribuir para a manutenção ou mudança das práticas vigentes.

A OV tem um importante papel na direção da mudança social ao propor uma reflexão sobre o futuro que cada sujeito busca construir não só individualmente, mas coletivamente. Costa (2007), a partir da sua experiência com OV em projetos sociais, destaca o potencial da orientação vocacional e profissional para promover mudanças na sociedade e reforça a importância desse tipo de trabalho para populações menos privilegiadas economicamente.

Um extenso levantamento, feito por Richard (2005), em torno das práticas eficazes em orientação vocacional realizadas em vários países revela que a orientação vocacional e de carreira tem se tornado uma prática amplamente difundida. O autor expõe que os programas e políticas que apresentam bons resultados incluem autoconhecimento, exploração vocacional, um método integrado e interativo de orientação e um contexto que oferece suporte ao 
participante. Tais resultados reforçam que o processo de orientação necessita de uma visão ampla e complexa. Portanto, as perspectivas unicamente psicométricas, individuais e na modalidade à distância não são suficientes para garantir eficácia de um trabalho que vise preparar o sujeito adequadamente para a escolha e para o futuro profissional. Nesse sentido, a perspectiva clínica soma-se à psicossocial ao contribuir para que cada sujeito seja considerado em suas necessidades individuais, avaliando as motivações internas para a escolha e facilitando o autoconhecimento.

Aliada ao olhar clínico e às reflexões sociais, a perspectiva desenvolvimentista permite compreender que a intervenção em OV não deve se limitar a uma faixa etária específica. Estudos mostram a relevância de se promover desenvolvimento vocacional em crianças, adolescentes, jovens e adultos (DIAS, 2009; MAGNUSON; STARR, 2000; TEIXEIRA; GOMES 2004). A compreensão e tendência atuais são de que o processo de OV deve ser desenvolvido ao longo de toda a vida, em uma proposta de orientação de carreira, e não somente na adolescência, por ocasião da realização do vestibular. Costa e Soares (2010) destacam a importância da orientação de carreira para pessoas em fase de aposentadoria, mas ressaltam e defendem um acompanhamento psicológico vocacional ao longo de toda a vida do sujeito.

A orientação vocacional e de carreira, portanto, tem por objetivo formar cidadãos conscientes da sua responsabilidade social e de si mesmos, capazes de pensar no próprio desenvolvimento com autonomia e autoconfiança. Faria e Taveira (2007) destacam a necessidade de os países investirem mais no desenvolvimento vocacional dos jovens uma vez que esta tem se mostrado eficaz. Relatórios da União Europeia e da OCDE - Organização para a Cooperação e Desenvolvimento Econômico apontam que a capacidade dos países de facilitar a transição da escola para o mundo do trabalho é um dos fatores que influencia a implementação de uma economia sustentável. Muitos países têm investido na orientação e desenvolvimento vocacional da sua população desde os primeiros anos escolares até a vida adulta, acreditando que tal política é precursora de desenvolvimento social e econômico (RICHARD, 2005). A orientação vocacional é tida como um investimento nos recursos humanos do país, gerando um impacto positivo na economia e na qualidade de vida geral da nação.

Nessa mesma direção, uma avaliação das políticas relativas à orientação de carreira em 37 países apurou que, dentro dos países analisados, tal prática está melhor implementada e desenvolvida nos países mais ricos (WATTS; SULTANA, 2004). Ainda assim, em todos os países avaliados, a OV é tida como algo de importância nacional porque contribui para o crescimento individual e coletivo. A pesquisa critica a prática mais corrente em OV, ou seja, de intervenção apenas 
no momento de crise de transição da escola para o trabalho. Destaca que o serviço deve ser oferecido desde a infância até a aposentadoria e deve se dar especial atenção aos momentos de transição na vida, sempre instrumentalizando os sujeitos a pensar e planejar suas carreiras, de acordo com o próprio crescimento e necessidades pessoais e as mudanças no mundo do trabalho.

O reconhecimento da OV pelos governos e países explicita a necessidade expressa por aqueles que vêem nesse tipo de trabalho um recurso valioso para o crescimento pessoal. Aguiar e Conceição (2009), em estudo sobre expectativa de futuro em 227 adolescentes de classe média alta na transição do ensino fundamental para o ensino médio, perceberam que os jovens têm interesse e sentem necessidade de orientação vocacional. Os adolescentes esperam que a escola possa suprir essa carência, uma vez que se percebem inseguros para encarar o mundo adulto e para empreenderem a escolha vocacional. Segundo estudo de Bardagi et al. (2006), universitários de final da graduação, prestes a entrarem no mercado de trabalho, também manifestam interesse por serviço de orientação vocacional e se mostram inseguros frente ao início da vida profissional.

A preparação para a escolha e o desenvolvimento profissional é uma prática que auxilia o trabalhador a se inserir no mercado competitivo nacional e internacional, no qual as exigências de qualificação são constantes e os índices de desemprego são alarmantes, tendo em vista um mundo globalizado. Os jovens ao deixarem a universidade, sem a devida preparação, cada vez mais esbarram em dificuldades no mercado de trabalho, muitas vezes ocupando subempregos, o que gera sofrimento e baixa da autoestima (DIAS, 2009).

Não ignorando as questões socioeconômicas, Soares, Dias e Baptista (2008) ponderam que a falta de sentido do trabalho é um dos fatores que impedem uma adequada inserção profissional e social, que pode muito bem estar associada a uma escolha profissional equivocada, não baseada em anseios pessoais e vocacionais, mas em outros fatores como necessidade, pressão de familiares e dos pares ou mera busca de status social. É muito importante que no momento da escolha ou no processo de gestão de carreira, o sujeito se conecte com o propósito e o sentido da tarefa que desempenha ou deseja realizar.

O trabalho, como um fator central na vida dos seres humanos, é uma forma de autoexpressão e do exercício da criatividade. O desemprego deixa jovens e adultos em situação de risco uma vez que impacta diretamente a noção de identidade e pode gerar resignação, autoestima negativa, desespero, vergonha, apatia, depressão, desesperança, sensação de futilidade, perda de objetivos, passividade, letargia e indiferença que, em muitos casos, resulta em violência, criminalidade e marginalização (SOARES et al., 2008). 
Assim, ter um trabalho contribui significativamente para a manutenção da saúde psicológica, é fator relevante na constituição da identidade e para a inclusão social e realização de sonhos pessoais (Maia; Mancebo, 2010).

Em suma, a orientação vocacional e de carreira pode ser associada a todas as idades e reconhecidamente contribui para o ganho de autonomia e autorresponsabilização, sendo de grande valia para o desenvolvimento profissional e pessoal dos indivíduos. Ao possibilitar o autoconhecimento, o pensamento crítico e uma maneira organizada de construção do futuro que agregue sentido ao existir, pode se esperar um aumento da qualidade de vida e saúde integral que extrapola os limites pessoais, atingindo o âmbito coletivo.

O período que compreende a adolescência ganha um destaque especial na questão vocacional por ser o momento em que boa parte dos jovens pensa e toma decisões sobre o futuro que quer construir. A pressão para a obtenção de resultados, para alcançar o sucesso e a falta de perspectiva de inserção profissional e social tem contribuído para o adoecimento da juventude.

\section{Adolescências e promoção da saúde integral}

Cabe destacar que quando se fala em adolescência de modo algum se faz referência a um fenômeno claramente delineado e generalizado para toda a população do Brasil, muito menos do mundo. Mais correto seria falar de adolescências, no plural, uma vez que esta etapa da vida acontece das formas mais variadas de acordo com o contexto socioeconômico e cultural no qual o sujeito está inserido. 0 Ministério da Saúde reconhece a diversidade das adolescências e as diferenças étnicas, sociais, culturais, econômicas, sexuais, religiosas presentes nessa população (BRASIL, 2010), deixando claro que a adolescência é um fenômeno biopsicossocial plural e "caracterizado por influências socioculturais que vão se concretizando por meio de reformulações constantes de caráter social, sexual e de gênero, ideológico e vocacional" (BRASIL, 2007, p. 8).

O desenvolvimento saudável dos jovens tem sido bastante prejudicado. Pesquisa realizada com 791 estudantes do 2 ㅇ e 3 o ano do ensino médio e de cursinho pré-vestibular particulares de Minas Gerais revelou que $45,7 \%$ da amostra apresentava sintomas depressivos e que tais sintomas se agravam progressivamente do 2 응 para o 30 ano, e deste para o cursinho (ROCHA et al., 2006). Os autores ponderam que as exigências sociais aliadas à puberdade podem ser um dos fatores que desencadeiam os sintomas depressivos. Desse modo, faz-se necessário o devido acompanhamento psicológico para lidar com essa fase de transição. Tais dados podem estar apontando o início de uma relação difícil 
entre o sujeito e o trabalho, desprovida de satisfação e realização, constituindo-se em campo fértil para adoecimentos mais graves.

Nessa esteira, um estudo realizado com 467 adolescentes gaúchos entre 15 e 20 anos, da rede de ensino público e privado, revelou correlação positiva entre indecisão, ansiedade e depressão (HUTZ; BARDAGI, 2006). Os adolescentes mais indecisos também apresentavam maiores índices de ansiedade e depressão. Não houve diferença significativa entre os alunos de escola pública e privada no que diz respeito à indecisão, mas sim que os alunos da rede pública se percebem menos capazes de atingirem seus anseios profissionais. O estudo ainda destaca que os pais têm papel preponderante no desenvolvimento vocacional e na saúde emocional dos filhos. Os autores reconhecem o sofrimento psíquico que os jovens vivem e enfatizam a necessidade de atentar para as questões emocionais e familiares no processo de escolha e orientação vocacional.

No campo das políticas públicas voltadas para jovens e adolescentes está se buscando uma mudança do assistencialismo para a prática de promoção da saúde. O documento mais recente do Ministério da Saúde, intitulado Diretrizes Nacionais para a Atenção Integral à Saúde de Adolescentes e Jovens na Promoção, Proteção e Recuperação da Saúde (BRASIL, 2010), reconhece que os jovens entre 15 e 24 anos fazem parte de um grupo de alta vulnerabilidade, exposto a uma série de situações de violência e perigo. 0 desemprego é um dos fatores que vem crescendo entre a população jovem brasileira, agravando os problemas sociais e a saúde integral dos indivíduos.

Os temas considerados estruturantes dessas diretrizes são: participação juvenil, equidade de gêneros, direitos sexuais e direitos reprodutivos, projeto de vida, cultura da paz, ética e cidadania e igualdade racial e étnica. Destaca-se a questão profissional, do projeto de vida e da participação dos jovens nas tomadas de decisão. O documento reconhece a importância da inserção profissional, desenvolvimento vocacional e construção da autonomia como fatores de promoção de qualidade de vida e saúde e essências para a realização do projeto futuro. O texto destaca e sugere a intervenção em grupo, valorizada como mais eficaz em relação à intervenção individual, quando se trata dessa faixa etária.

A partir das diretrizes do Ministério da Saúde (BRASIL, 2010), compreende-se a promoção da saúde integral para adolescentes como uma perspectiva que percebe o sujeito como um todo, reconhecendo que há uma interdependência entre as diversas áreas da vida, familiar, escolar, profissional, afetiva, etc. Desse modo, todos os aspectos do sujeito contribuem para a melhoria ou agravo da qualidade de vida geral e da saúde. O olhar para a saúde integral implica em reconhecer a pluralidade das experiências de vida dos indivíduos e suas necessidades diversas. Promover saúde com 
adolescentes e jovens "é considerar seus projetos de vida, é valorizar sua participação e o desenvolvimento de sua autonomia, é acreditar que eles e elas aprendem a lidar com os seus problemas e com seu contexto de vida" (BRASIL, 2010, p. 79). O trabalho dos agentes de saúde é, portanto, dar apoio e suporte para que o jovem possa se desenvolver dentro das próprias necessidades.

É importante a compreensão de que a saúde é o resultado de diversos fatores que estão presentes na vida dos sujeitos e que, muito mais do que ausência de doenças, se trata da busca por satisfação e qualidade de vida. Pesquisadores identificaram correlação positiva entre saúde, felicidade e satisfação com a vida entre adolescentes de Portugal (SIMÕES et al., 2008). Os fatores individuais que promovem saúde e felicidade estavam associados à prática de atividade física, à alimentação e à ausência de comportamentos de risco. Já os fatores sociais associados à saúde e felicidade dizem respeito às relações interpessoais em contexto significativo para o participante, como a família e a escola. Os autores destacaram a importância da promoção da saúde entre adolescente que inclua o desenvolvimento de competências sociais e de comportamentos de saúde que diminuam comportamentos de risco.

Uma das dificuldades das políticas de promoção da saúde é que normalmente os serviços de saúde são buscados pela população quando da presença de algum agravo, o que reforça o caráter assistencialista de tais programas. Quando se pensa em promoção da saúde espera-se que sejam desenvolvidas uma série de ações que previnam o agravo e permitam um desenvolvimento mais saudável. Formigli, Costa e Porto (2000) avaliaram um serviço voltado para a saúde integral do adolescente em Belém-PA que, apesar de se mostrar bastante eficaz em vários requisitos, realizava atendimentos basicamente com o objetivo assistencialista e curativo, no lugar do preventivo.

Portanto, a promoção da saúde integral da população jovem influencia diretamente o desenvolvimento socioeconômico principalmente por se tratar do grupo que representa o futuro, seja enquanto profissionais ou sujeitos (re)produtores da cultura. Os adolescentes e jovens estão carecendo de atenção e cuidados, apresentando uma saúde psicológica e social prejudicada pelo contexto micro e macro, que envolve inseguranças e incertezas quanto à própria capacidade de enfrentar os desafios e de se inserir no mundo adulto e produtivo.

\section{Vocação, protagonismo e saúde}

As questões relativas ao trabalho têm importância significativa e causam visível impacto na qualidade de vida dos sujeitos. A 
dificuldade de inserção profissional, a falta de sentido no trabalho e na vida e os processos biopsicossociais presentes nos jovens durante a puberdade, associados à insegurança, à indecisão e à falta de confiança nas próprias capacidades criam um terreno fértil para um adoecimento geral. São necessárias práticas que possibilitem caminhos mais saudáveis. A orientação vocacional e de carreira se mostra como solução possível diante desse quadro.

Considerando os resultados de alguns estudos no Brasil, Aguiar e Conceição (2008) apontam que após intervenção de orientação vocacional em grupo de estudantes do ensino médio da rede pública, os adolescentes estavam com concepções menos imaturas e fantasiosas sobre a realidade e se sentiam mais seguros e confiantes em relação ao futuro e à escolha profissional. Almeida (2006), ao avaliar um serviço de orientação vocacional sob a perspectiva de exorientandos, constatou que os participantes consideraram positivamente o serviço, como promotor de maior autoconhecimento e maturidade para a escolha profissional.

Lopes (2006) realizou um trabalho de orientação vocacional com jovens com déficit cognitivo e observou aumento de habilidades sociais e mais autonomia para a escolha. Tais estudos apontam para o potencial da orientação vocacional ao despertar elementos que podem contribuir ativamente para a saúde integral dos participantes. Depreende-se dos estudos que a OV tem trazido contribuições para o desenvolvimento da autoconfiança e da maturidade e para o planejamento de carreira dos sujeitos. Tais elementos facilitam a entrada no mercado de trabalho e a relação do indivíduo consigo mesmo e com a realidade circundante, o que impactará sobre o bemestar geral do jovem e favorecerá a adoção de uma relação positiva com a vida.

Os estudos nacionais corroboram com os achados internacionais no que diz respeito à eficácia da orientação vocacional e de carreira em melhorar a saúde dos participantes. Na Finlândia, pesquisa com alunos do 9o ano que visava avaliar o efeito de uma intervenção em saúde mental e preparação para a transição do ensino fundamental para o médio apurou que, após a intervenção, alguns adolescentes apresentaram menos sintomas depressivos e outros diminuíram o risco de esgotamento (burn-out). Entretanto não houve dados estatisticamente significativos que suportassem a hipótese de que as intervenções promoveriam saúde mental em todos os participantes (VUORI et al., 2008). Nesse caso, o efeito foi mais significativo naqueles jovens que se encontravam em maior situação de risco do que a média.

Skorikov (2007) apresenta resultados de estudo com 389 adolescentes havaianos e conclui que trabalhos de preparação de carreira são eficazes no ajustamento dos participantes, principalmente no que diz respeito ao bem-estar psicológico e à 
integração social. Turner e Conkel (2010) relatam os resultados de uma intervenção com adolescentes na Austrália baseada no desenvolvimento de uma série de habilidades pessoais, sociais e decisionais. Os participantes desenvolveram autoconceito mais positivo, se instrumentalizaram para lidar com a inserção no mundo do trabalho e perceberam maior suporte emocional em relação ao grupo controle, que não passou por qualquer atividade de orientação. A esta altura pode-se traçar nitidamente uma afinidade entre as propostas de orientação vocacional e de carreira e a promoção da saúde integral entre adolescentes. Percebe-se que a orientação vocacional e de carreira aqui defendida, que tem como referência o autoconhecimento - ancorado na psicologia clínica, em especial na perspectiva neoreichiana -, a perspectiva desenvolvimentista e a responsabilidade social como constructo sócio-histórico, possibilita muito mais que uma escolha ajustada e adequada aos desejos e características pessoais. Seu fim último é estimular os indivíduos a serem protagonistas do seu próprio destino, de seu crescimento e de transformações sociais.

$\mathrm{Na}$ intersecção entre a orientação vocacional e de carreira e a promoção da saúde encontra-se o conceito de protagonismo juvenil. Por protagonismo entende-se o desempenho da capacidade do sujeito de participar ativamente e ser autor da própria vida e das transformações que quer ver no mundo. O sujeito é alçado ao papel de co-responsável pelo seu desenvolvimento e é reconhecido como capaz de atingir os seus objetivos. Favorecer o protagonismo é uma estratégia eficaz de promoção da saúde e é um caminho promissor para dar conta das necessidades sociais e pessoais do adolescente (BRASIL, 2010; FERRETTI et al., 2004). O protagonismo ainda favorece o desenvolvimento de autoestima positiva e da saúde integral, o empoderamento dos jovens enquanto agentes de mudança e a formulação de um projeto de vida (BRASIL, 2010).

Tem sido crescente o reconhecimento do valor da juventude como um grupo promissor no processo de transformação social. De acordo com Meirelles e Ruzany (2008), o potencial crítico, criativo, inovador e participativo da juventude, quando adequadamente canalizado, pode redundar em mudanças positivas. Por sua vez, as autoras lembram que a conexão que se faz entre promoção de saúde e protagonismo juvenil apoia-se no processo de educação e saúde para a cidadania e, por sua vez, o paradigma que norteia a ação do "protagonismo juvenil" fundamenta-se num modelo de relação pedagógica pautada na solidariedade entre os adultos e os mais jovens.

Esta relação significa a base essencial do processo de intercâmbio entre educadores (profissionais) e educandos (jovens). A partir desse convívio democrático, o jovem vai 
aprendendo a pensar e agir, adquirindo assim, diante da complexa realidade político-social de nosso tempo, melhores condições para decidir de forma autônoma, madura e responsável (MEIRELLES; RUZANY, 2008, p. 37).

De acordo com as autoras, deve-se criar condições para que o jovem possa exercitar, de forma coletiva e crítica, as faculdades demandadas na construção gradativa da autonomia que ele exercerá no mundo adulto. Incentivar o protagonismo juvenil significa capitalizar a tendência dos adolescentes na formação de grupos, em prol de seu desenvolvimento pessoal e social. Para tanto, os adultos devem deixar espaços para que os adolescentes possam adotar outras formas de organização e de expressão e que possam construir espaços de sociabilidade espontânea para enfrentar os dilemas e as contradições da sociedade adulta.

\begin{abstract}
Apesar de os jovens serem frequentemente colocados como agentes do presente, eles ainda dispõem de poucos espaços para participar da vida política e social de sua comunidade. Para alcançar a mudança social devem assumir o papel de protagonistas pelo menos em três enfoques: políticas públicas, práticas sociais e direito/legislação. Mesmo vivendo numa época de mudanças aceleradas, muitos jovens estão à procura de situações e de experiências que os ajudem a encontrar o sentido de sua existência, ávidos para participar na construção de um projeto de vida melhor, bastando encontrar espaços para fazer valer suas ideias (MEIRELLES; RUZANY, 2008, p. 39).
\end{abstract}

A escola é um local privilegiado para o estímulo ao protagonismo e para o desenvolvimento de práticas de orientação vocacional. Segundo Boghossian e Minayo (2009), a formação para a cidadania nas escolas é apontada como prioritária pelos autores nacionais e de língua inglesa, no sentido de criar sustentabilidade e mudanças significativas na promoção do direito de participação da juventude.

A orientação vocacional que promove o protagonismo apresenta grande potencial para facilitar as mudanças sociais, que por fim impactarão na saúde integral. Adolescentes vivendo em áreas de risco e expostos a todo tipo de violência e abuso de substâncias químicas vêem a inserção cultural e profissional como um meio de melhorar de vida (MUZA; COSTA, 2002). Nos projetos de promoção da saúde é importante que se criem espaços que permitam o desenvolvimento da autonomia e do autocuidado, dando margem para a ressignificação das experiências de vida, das possibilidades futuras e da viabilidade de inserção social.

Entretanto, cabe uma ressalva importante. Uma armadilha é a ênfase exagerada na questão individual ou coletiva da superação das dificuldades, podendo reproduzir o discurso que responsabiliza 0 
sujeito pelo seu sucesso ou fracasso e ignora os fatores socioeconômicos, dando margem à omissão governamental. Portanto, não se podem ignorar as perversidades subjacentes ao discurso ideológico do sistema capitalista e dos modelos de sucesso vigentes, que nitidamente segregam e limitam o acesso de muitos ao que é considerado melhor e elevador do status social.

O protagonismo não deve ser acrítico e simplesmente buscar moldar os jovens de acordo com as exigências da cultura e do sistema (FERRETTI et al., 2004). Ao contrário, a ênfase recai sobre a construção, com responsabilidade social, do próprio caminho de vida, de acordo com as necessidades reais do indivíduo. Nesse rumo, cada um pode desenvolver os próprios valores e talentos sempre articulados com o compromisso de transformação social e participação ativa na resolução dos problemas coletivos, o que resultará em um indivíduo que possui autonomia para tomar suas decisões e se desenvolver.

A orientação vocacional aqui exposta está longe de ver aquele que dela participa como um paciente ou vítima do processo de orientação. Espera-se que o indivíduo construa autonomia e que isto contribua no seu processo de desenvolvimento para assumir as rédeas da própria vida.

Forma-se assim, cidadãos conscientes do espaço que ocupam na sociedade e da capacidade de co-construirem a realidade em que vivem. Desse modo, uma orientação vocacional que coloca a pessoa no centro do processo, dando a ela voz para que questione e construa o trabalho de orientação vocacional, é uma OV que estimula o protagonismo e promove saúde.

\section{Considerações finais}

Inicialmente pensou-se em articular a orientação vocacional com a promoção da saúde mental. Entretanto, para evitar a dicotomia entre psique e corpo - já muito antiga no discurso e antiquada em vistas do atual desenvolvimento científico e humano, preferiu-se o termo Saúde Integral, adotado pelo Ministério da Saúde. Entende-se que o indivíduo deve ser percebido de forma holística e que todas as áreas da vida se interrelacionam e compõem o todo que é o sujeito.

A ausência ou precariedade dos projetos de vida que façam sentido ou a dificuldade de inserção no mercado de trabalho afetam a vida do sujeito em vários aspectos, prejudicando a saúde como nos âmbitos biológicos, psicológicos e sociais (SOARES et al., 2008). Tal adoecimento tem repercussões diretas na qualidade de vida individual e coletiva, uma vez que abre espaço para a marginalização, a violência e a adoção de comportamentos de riscos. Tal quadro 
sinaliza, de fato, a grave situação em que se encontra nossa sociedade e a urgência de ações transformadoras.

Seja nacional ou internacionalmente, seja no meio acadêmico, administrativo ou na gestão pública, as práticas de orientação vocacional, profissional e de carreira têm ganhado destaque e têm seu valor reconhecido para o desenvolvimento individual e coletivo. Diante das necessidades expressas nos documentos do Ministério da Saúde e da vulnerabilidade em que se encontra a juventude brasileira, a proposta da OV se mostra útil e valiosa sendo um recurso na promoção do protagonismo e, portanto, da saúde dos jovens.

No que concerne especificamente o público adolescente, destaca-se a importância de trabalhos em grupo que atuem incluindo 0 autoconhecimento, a dimensão psicossocial e o desenvolvimento de habilidades que estimulem nos jovens o protagonismo para que este seja capaz de construir planos de vida com confiança e otimismo. Enfatiza-se a importância da reflexão crítica sobre os modelos de produção vigentes e sobre a lógica de sucesso exigida à juventude. Reforça-se ainda a importância de buscar sentido para o trabalho e para a ocupação e de acompanhar, desde a infância até a aposentadoria, o desenvolvimento vocacional de cada indivíduo.

Alguns autores reconhecem que é necessária uma maior produção científica na área de orientação vocacional e de carreira (GUICHARD, 2001; RICHARD, 2005; WATTS; SULTANA, 2004). Pesquisadores e orientadores em todo mundo têm trabalhado usando diferentes metodologias, nomenclaturas e referenciais teóricos, o que revela a diversidade de práticas de OV existentes e suas muitas possibilidades de aplicação.

Reconhecidamente, a orientação vocacional e de carreira tem contribuído para o desenvolvimento pessoal e social no mundo. As intervenções são capazes de promover impacto positivo na autoestima e na autonomia, de facilitar a inserção social e profissional e de possibilitar a elaboração de projetos de vida carregados de sentido. Compreende-se que a construção de uma proposta de OV que vise a integração com as políticas de atenção à saúde integral dos adolescentes deve estar firmemente apoiada na literatura científica atual, com referenciais teóricos claros e consistentes.

\section{Referências}

ABADE, F. A. L. Orientação profissional no Brasil: uma revisão histórica da produção científica. Revista Brasileira de Orientação Profissional, Ribeirão Preto, v. 6, n. 1, p. 15 - 24, 2005.

AGUIAR, F. H. R.; CONCEIÇÃO, M. I. G. A Orientação Vocacional na 
perspectiva neo-reichiana: contribuições do grounding. Revista Brasileira de Orientação Profissional, Ribeirão Preto, v. 9, n. 1, p. 115-128, 2008.

. Expectativas de futuro e escolha vocacional em estudantes na transição para o ensino médio. Revista Brasileira de Orientação Profissional, Ribeirão Preto, v. 10, n. 2, p. 105-115, 2009.

ALMEIDA, F. H. Avaliação de um serviço de orientação profissional: a perspectiva de ex-usuários. Revista Brasileira de Orientação Profissional, Ribeirão Preto, v. 7, n. 2, p. 81-102, 2006.

BARDAGI, M.; LASSANCE, M. C. P.; PARADISO, A. C.; MENEZES, I. A. Escolha profissional e inserção no mercado de trabalho: percepções de estudantes formandos. Psicologia Escolar e Educacional, Campinas, v. 10, n. 1, p. 69-82, 2006.

BOGHOSSIAN, C. O.; MINAYO, M. C. Revisão sistemática sobre juventude e participação nos últimos 10 anos. Saúde e Sociedade, São Paulo, v. 18, n. 3, p. 411-423, 2009.

BRASIL. Marco legal: saúde, um direito de adolescentes. Brasília: Editora do Ministério da Saúde, 2007.

- Diretrizes nacionais para a atenção integral à saúde de adolescentes e jovens na promoção, proteção e recuperação da saúde. Brasília: Editora do Ministério da Saúde, 2010.

COSTA, A. B.; SOARES, D. H. P. Orientação psicológica para a aposentadoria. Revista Psicologia: Organizações e Trabalho, Brasília, v. 9, n. 2, p. 97-108, 2010.

COSTA, J. M. Orientação profissional: um outro olhar. Psicologia USP, São Paulo, v. 18, n. 4, p. 79-87, 2007.

DIAS, M. S. L. Sentidos do trabalho e sua relação com o projeto de vida de universitários, 2009. 272f. Tese (Doutorado em Psicologia) - Programa de Pós-graduação em Psicologia, Universidade Federal de Santa Catarina, Florianópolis, 2009.

FARIA, L.; TAVEIRA, M. D. C. Vale a pena investir na consulta psicológica vocacional? Revisão de estudos e suas implicações. In: CONGRESSO INTERNACIONAL GALEGO-PORTUGUÊS DE PSICOPEDAGOGÍA: ACTAS, 2007, Coruña. Disponível em: <http://repositorium.sdum.uminho.pt/handle/1822/7439>. Acesso em: 18 out. 2010.

FERRETTI, C. J.; ZIBAS, D. M.; TARTUCE, G. Protagonismo juvenil na literatura especializada e na reforma do ensino médio. Cadernos de Pesquisa, São Luís, v. 34, n. 122, p. 411-423, 2004.

FORMIGLI, V. L.; COSTA, M. C.; PORTO, L. A. Avaliação de um serviço de atenção integral à saúde do adolescente. Cadernos de Saúde Pública, Rio de Janeiro, v. 16, n. 3, p. 831-841, 2000.

GUICHARD, J. A century of career education: review and perspectives. International Journal for Educational and 
Vocational Guidance, Dordrecht, v. 1, n. 3, p. 155-176, 2001.

HUTZ, C. S.; BARDAGI, M. P. Indecisão profissional, ansiedade e depressão na adolescência: a influência dos estilos parentais. PsicoUSF, São Franscisco, v. 11, n. 1, 2006.

LEVENFUS, R. S.; BANDEIRA, D. R. Avaliação dos interesses profissionais (AI P). São Paulo: Vetor, 2009.

LOPES, L. A orientação profissional para jovens com déficit cognitivo: um relato de experiência. Boletim de Psicologia, São Paulo ,v. 56, n. 125, p. 189-203, 2006.

MAGNUSON, C. S.; STARR, M. F. How early is too early to begin life career planning? The importance of the elementary school years. J ournal of Career Development, Columbia, v. 27, n. 2, p. 89-101, 2000.

MAIA, A. A. R. M.; MANCEBO, D. Juventude, trabalho e projetos de vida: ninguém pode ficar parado. Psicologia: Ciência e Profissão, Brasília, v. 30, n. 2, p. 376-389, 2010.

MEIRELLES, Z. V. M.; RUZANY, H. Promoção de Saúde e protagonismo juvenil. In: MINISTÉRIO DA SAÚDE (Org.). Saúde do adolescente: competências e habilidades. Brasília: Editora do Ministério da Saúde, 2008, p. 35-40.

MUZA, G. M.; COSTA, M. P. Elementos para a elaboração de um projeto de promoção à saúde e desenvolvimento dos adolescentes: o olhar dos adolescentes. Cadernos de Saúde Pública, Rio de Janeiro, v. 18, n. 1, p. 321-328, 2002.

PASQUALINE, J. C.; GARBULHO, N. F.; SCHUT, T. Orientação profissional com crianças: uma contribuição à educação infantil. Revista Brasileira de Orientação Profissional, Ribeirão Preto, v. 5, n. 1, p. 71-85, 2004.

RICHARD, G. V. International best practices in career development: review of the literature. International Journal for Educational and Vocational Guidance, Dordrecht, v. 5, n. 2, p. 189-201, 2005. ROCHA, T. H.; RIBEIRO, J. E.; PEREIRA, G. A.; AVEIRO, C. C.; ALÉMMAR, S. L. Sintomas depressivos em adolescentes de um colégio particular. Psico USF, São Francisco, v. 11, n. 1, p. 95-102, 2006.

SIMÕES, C.; MATOS, M. G.; BATISTA-FOGUET, J. Saúde e felicidade na adolescência: factores individuais e sociais associados às percepções de saúde e de felicidade dos adolescentes portugueses. Revista Brasileira de Terapias Cognitivas, Rio de Janeiro, v. $4, \mathrm{n}$. 2, p. 19-38, 2008.

SKORIKOV, V. Continuity in adolescent career preparation and its effects on adjustment. J ournal of Vocational Behavior, Rootstown, v. 70, n. 1, p. 8-24, 2007.

SOARES, D. H. P.; DIAS, M. S. L.; BAPTISTA, I. Situações de risco: jovens "sem projeto de vida", a construção de um objeto de estudo. Cadernos de Pedagogia Social: Educação e Solidariedade, Porto, v. 2, p. 163-178, 2008. 
TEIXEIRA, M. A. P.; GOMES, W. B. Estou me formando... e agora?: Reflexões e perspectivas de jovens formandos universitários. Revista Brasileira de Orientação Profissional, Ribeirão Preto ,v. 5, n. 1, p. 47-62, 2004.

TURNER, S. L.; CONKEL, J. L. Evaluation of a career development: skills intervention with adolescents living in an inner city. Journal of Counseling \& Development, Alexandria, v. 88, n. 4, p. 457-465, 2010.

VUORI, J.; KOIVISTO, P.; MUTANEN, P.; JOKISAARI, M.; SALMELAARO, K. Towards working life: effects of an intervention on mental health and transition to post-basic education. Journal of Vocational Behavior, Rootstown, v. 72, n. 1, p. 67-80, 2008. WATTS, A. G.; SULTANA, R. G. Career guidance policies in 37 countries: contrasts and common themes. International J ournal for Educational and Vocational Guidance, Dordrecht, v. 4, n. 2, p. 105-122, 2004.

\section{Endereço para correspondência}

Fernando Henrique Rezende Aguiar

SGAS 915 Ed. Office Center BI. C sala 303

CEP: 70390-150 - Brasília - DF - Brasil

Endereço eletrônico: fhaguiar@gmail.com

Maria I nês Gandolfo Conceição

Universidade de Brasília, Instituto de Psicologia, Professora Adjunta

Departamento de Psicologia Clínica - Instituto de Psicologia, ICC Sul, Campus

Universitário Darcy Ribeiro - Brasília - DF - Brasil.

CEP 70910-900

Endereço eletrônico: inesgand@unb.br

Recebido em: 18/04/2011

Reformulado em: 04/11/2011

Aceito para publicação em: 20/12/2011

Acompanhamento do processo editorial: Eleonôra Torres Prestelo

\section{Notas}

* Mestre em Psicologia Clínica e Cultura. Bolsista CAPES.

**Professora Associada do Instituto de Psicologia da Universidade de Brasília 